\title{
Prevalence of depression among women with obstetric fistula: A systematic review and meta- analysis Berhanu Boru Bifftu [BBB] 1*and Yonas Deressa Guracho [YDG]2
}

Berhanu Boru Biftu ( $\sim$ berhanuboru@gmail.com )

University of Gondar

Yonas Deressa Guracho

Bahir Dar University

Research article

Keywords: Co-morbidity, Depression, Obstetric Fistula

Posted Date: March 18th, 2020

DOI: https://doi.org/10.21203/rs.3.rs-17602/v1

License: (c) (i) This work is licensed under a Creative Commons Attribution 4.0 International License.

Read Full License 


\section{Abstract}

Objective Obstetric fistula is one of the most devastating birth injuries, affecting up to 3.5 million women. Depression is the priority mental disorders affecting up to $98 \%$ the patient living with obstetric fistula and adversely affects their quality of life. Inconsistent reported prevalence of depression and dearth of comprehensive meta-analysis need an up to date evidence for decision makers. Thus, the purpose of this meta-analysis was to determine the pooled prevalence of depression among women with obstetric fistula.

Methods Databases including PubMed, Cochrane Library and SCOPUS were searched. Heterogeneity across the studies was assessed by Cochrane chi-square ( $\chi 2)$ and quantified by I 2 statistics test. Funnel plots and Egger's test were used to determine publication bias. Sensitivity test and subgroup analysis were also performed. The pooled prevalence of depression was calculated using random effects model and Dersimonian and Laird method.

Results Fifteen eligible studies were included in the study. The pooled prevalence of depression was found to be $72 \%$ ( $95 \% \mathrm{Cl} ; 60 \%-83 \%$ ). We found evidence of significant heterogeneity ( $2=95.64 \%$ and $p<$ $0.001)$. Sensitivity test showed none of the point estimates was outside of the overall $95 \% \mathrm{Cl}$. No evidence of publication bias egger's test $(p=0.654)$.

Conclusion Around three fourth of women with obstetric fistula experienced depression. Thus, authors' suggest the need of special attention to mange co-morbid depression among women with obstetric fistula, such as an integrated mental health care.

\section{Background}

Obstetric fistula is an abnormal opening between bladder and the vagina or between rectum and the vagina which causes urinary or faecal or both (urinary and faecal) incontinence (1-3). Poverty, early marriage, childbirth and lack of access to obstetric service are the contributing factors for the developments of obstetric fistula (4-7). Global, the prevalence of obstetric fistula ranged from 1 to 3.5 million $(3,8-11)$.

The consequence of untreated obstetric fistula, include but not limited to vaginal wetness, infections, bad odour, skeletal and cervical injuries, amenorrhoea, vaginal scarring and stenosis, infertility and fetal death $(1-3,12-16)$ affect the overall woman's quality of life $(14,17-21)$. This constant leakage of urine, faeces, or both also affects the psycho-social quality of women's lives. Of these, depression is one of the most common disorders affecting up to $98 \%$ of individual with obstetric fistula $(12,14,17-20,22-35)$. Depression is the priority mental disorders, which carry public health burden $(26,36)$, particularly for those of high risk group like women with obstetric fistula $(19,20,28,29,37,38)$, where majority of them were suffering with poor socio-economic status, unemployment and traumatic life events $(14,27,39,40)$ divorced marital status, and lack of social support $(12,28,37)$, the incidence and persistence of depression is high with an estimated prevalence ranging from $25-98 \%(14,18,28-30,37,38,41-43)$. This co-morbidity of depression had a wide range of adverse effect on the healing process of the wound, 
incidence of other physical illness, substance use, treatment and suicide $(22-27,44,45)$. In the context of these discrepancies in the reported individual studies, there is a need of a comprehensive quantitative meta-analysis. The objective of this meta-analysis was to determine the pooled prevalence of depression among women with obstetric fistula.

\section{Methods}

This systematic review and meta-analysis was conducted in accordance with the Preferred Reporting Items for Systematic Review and Meta-Analysis (PRISMA)(46) guideline

\section{Search strategy}

A compressive search of electronic databases PubMed/Medline, Cochrane Library and SCOPUS (Elsevier) were conducted without time, country and language restrictions. Keywords were used to search PubMed/Medline, Cochrane Library and SCOPUS. Additional Medical Subject Headings (MeSH) terms were formulated for use in PubMed. Combinations of MeSH thesaurus and text words combining with appropriate Boolean operators were used. Index terms were utilized in to SCOPUS (EV ensure that all relevant articles were retrieved. Reference lists of all articles were also searched. Moreover, a grey literature search for additional unpublished sources was conducted at Google scholar. All searches were performed until June, 01, 2019. PubMed/MEDLINE database was searched using the following search terms and search strategy: ((depressive disorders [MeSH Terms]) OR (depressive disorders) OR (depressive symptoms [MeSH Terms]) OR (depressive symptoms) AND ((associated factors [MeSHTerms]) OR (associated factors) OR (determinant factors [MeSH Terms]) OR (determinant factors) AND (( vesico-vaginal fistula [MeSH Terms]) OR (vesico-vaginal fistula) OR (obstetric fistula [MeSH Terms]) OR (obstetric fistula) OR ( recto-vaginal fistula [MeSH Terms]) OR (recto-vaginal fistula) OR (urogenital fistula [MeSH Terms]) OR (urogenital fistula)).

\section{Selection of studies}

All articles retrieved through search strategy were imported to EndNote X7 (Thomson Reuters, New York, USA). After excluding the duplicated studies from EndNote Library, the title and abstracts of the remaining articles were assessed independently by two reviewers (BBB and YDG) and disagreements were resolved by discussion. Conference abstracts, letters to editors, review, and commentary articles were excluded.

\section{Eligibility criteria}

\section{Participants}

This review targets women with obstetric fistula.

\section{Outcome measure}

This review included studies that investigated the prevalence of depression using standardized assessment tool. 


\section{Study design}

Observational studies (cross-sectional and cohort/longitudinal) were included in this systematic review and meta-analysis. For follow up studies, we included the base line results. Studies that focused on case reports, conference and abstract were excluded.

\section{Quality assessment}

The methodological quality of included studies was assessed by two independent reviewers (BBB and YDG) using the Joanna Briggs Institute Meta-analysis of Statistics Assessment and Review Instrument (JBI-MAStARI) critical appraisal tool for prevalence studies (47). This JBI quality assessment tool has response option of "yes", "no", "unclear" and "not applicable". The overall quality of the study was determined based on the overall mean and define as "high risk" for score $\geq$ mean and "low risk" for score $<$ mean. Disagreements were solved by discussion.

\section{Data extraction}

Data were extracted from the eligible studies by two independent reviewers (BBB and YDG) using a preconceived data abstraction form and any disagreements were resolved by discussion. We extracted the following data items from each articles: name of the first author, year of publication, study area/region, study design, study population, data collection tool, sample size and number of cases/prevalence of depression.

\section{Data analysis}

The extracted data were entered into a Micro-soft Excel Database and then exported into Stata 14 that we installed packages for meta-analyses online. Pooled prevalence of depression was calculated using metaprop command with a random-effects model (48) using the Dersimonian and Laird method based on the transformed values and their variance (49). We fit the Freeman-Tuckey variant of the arcsine square root transformation of proportions to avoid variance instability when handling proportions close to one (50). The score test-based confidence interval was used for the proportions of depression. Test for Heterogeneity was performed using Cochran's $Q$ statistic and the $I^{2}$ statistics. $I^{2}$ value greater than $50 \%$ was considered as indicative of substantial heterogeneity (51). Sub-group analysis was performed by sample size and study quality, year of publication, assessment tool and country. Evidence of publication bias was tested using visual inspection of the symmetry in funnel plot (52) and Egger's tests (53). A sensitivity analysis was conducted to examine influential study.

\section{Results}

The initial database literature search resulted in 296 published articles. Additional, 28 studies were located through other source. Finally, the overall literature search resulted in 324 articles. Of these articles, 152 were excluded during the initial assessments as their title was found to be irrelevant. Of the remaining 172 studies, 91 were excluded through abstract reading because of different outcome. Finally, 
66 papers were excluded because of different methods and unclear reports. Thus, the remained 15 studies were included in the systematic review and meta-analysis (Fig. 1).

\section{Study characteristics}

A total of 15 studies, including data from 1275 participants, were included in this systematic review and meta-analysis. The included studies were obtained from six different countries: Ethiopia $(n=5)$, Tanzania $(n=5)$, Sudan (2), Kenya $(n=1)$, Uganda $(n=2)$ and Nigeria $(n=1)$. All studies utilized institution based cross-sectional study design. Depression was assessed using four different assessment tool such as: GHQ-28 $(n=3), \operatorname{BDI}-21(n=3)$, CES-D $(n=4), H S C(n=1)$ and PHQ-9 $(n=4)$ (Table 1$)$. The overall quality score of included studies ranged from 5 to 8 (overall average 6.5). Of these, seven studies had low risk of bias and the remaining eight studies had high risk of bias (Table: 1 ). 
Table 1

Characteristics of the studies

\begin{tabular}{|c|c|c|c|c|c|c|c|c|}
\hline $\begin{array}{l}\text { Author, } \\
\text { Year }\end{array}$ & Country & Design & Outcome & Tool & $\begin{array}{l}\text { Sample } \\
\text { size }\end{array}$ & $\begin{array}{l}\text { No. } \\
\text { of } \\
\text { cases }\end{array}$ & prevalence & Quality \\
\hline $\begin{array}{l}\text { Zeleke } \\
, 2013\end{array}$ & Ethiopia & CS & Depression & $\begin{array}{l}\text { BDI- } \\
21\end{array}$ & 37 & 36 & 97 & $\begin{array}{l}\text { High } \\
\text { risk }\end{array}$ \\
\hline $\begin{array}{l}\text { Tewolde, } \\
2015\end{array}$ & Ethiopia & CS & Depression & $\begin{array}{l}\text { BDI- } \\
21\end{array}$ & 40 & 39 & 98 & $\begin{array}{l}\text { Low } \\
\text { risk }\end{array}$ \\
\hline $\begin{array}{l}\text { Belayihun, } \\
2018\end{array}$ & Ethiopia & CS & Depression & $\begin{array}{l}\text { BDI- } \\
21\end{array}$ & 219 & 127 & 58 & $\begin{array}{l}\text { Low } \\
\text { risk }\end{array}$ \\
\hline $\begin{array}{l}\text { Nweke } \\
\text {,2017 }\end{array}$ & Nigeria & CS & Depression & $\begin{array}{l}\text { GHQ- } \\
28\end{array}$ & 100 & 37 & 73 & $\begin{array}{l}\text { Low } \\
\text { risk }\end{array}$ \\
\hline $\begin{array}{l}\text { Djengbed, } \\
2014\end{array}$ & Sudan & CS & Depression & $\begin{array}{l}\text { CES- } \\
\text { D }\end{array}$ & 60 & 43 & 37 & $\begin{array}{l}\text { High } \\
\text { risk }\end{array}$ \\
\hline $\begin{array}{l}\text { Weston } \\
, 2011\end{array}$ & Kenya & CS & Depression & $\begin{array}{l}\text { PHQ- } \\
9\end{array}$ & 70 & 51 & 72 & $\begin{array}{l}\text { High } \\
\text { risk }\end{array}$ \\
\hline $\begin{array}{l}\text { Saadalla } \\
, 2016\end{array}$ & Sudan & CS & Depression & $\begin{array}{l}\text { GHQ- } \\
28\end{array}$ & 100 & 41 & 41 & $\begin{array}{l}\text { High } \\
\text { risk }\end{array}$ \\
\hline $\begin{array}{l}\text { Watt } \\
, 2017\end{array}$ & Tanzania & CS & Depression & $\begin{array}{l}\text { CES- } \\
\text { D }\end{array}$ & 60 & 40 & 87 & $\begin{array}{l}\text { High } \\
\text { risk }\end{array}$ \\
\hline $\begin{array}{l}\text { Wilson, } \\
2015\end{array}$ & Tanzania & CS & Depression & $\begin{array}{l}\text { CES- } \\
\text { D }\end{array}$ & 54 & 14 & 67 & $\begin{array}{l}\text { High } \\
\text { risk }\end{array}$ \\
\hline $\begin{array}{l}\text { Wilson, } \\
2016\end{array}$ & Tanzania & CS & Depression & $\begin{array}{l}\text { CES- } \\
\text { D }\end{array}$ & 28 & 8 & 39 & $\begin{array}{l}\text { High } \\
\text { risk }\end{array}$ \\
\hline $\begin{array}{l}\text { Dennis, } \\
2016\end{array}$ & Tanzania & CS & Depression & $\begin{array}{l}\text { CES- } \\
\text { D }\end{array}$ & 59 & 23 & 74 & $\begin{array}{l}\text { Low } \\
\text { risk }\end{array}$ \\
\hline $\begin{array}{l}\text { Tsegaw, } \\
2018\end{array}$ & Ethiopia & CS & Depression & $\begin{array}{l}\text { PHQ- } \\
9\end{array}$ & 167 & 124 & 91 & $\begin{array}{l}\text { Low } \\
\text { risk }\end{array}$ \\
\hline $\begin{array}{l}\text { Belayihun, } \\
2019\end{array}$ & Ethiopia & CS & Depression & $\begin{array}{l}\text { PHQ- } \\
9\end{array}$ & 200 & 182 & 28 & $\begin{array}{l}\text { Low } \\
\text { risk }\end{array}$ \\
\hline $\begin{array}{l}\text { Ayadi, } \\
2019\end{array}$ & Uganda & CS & Depression & HSC & 60 & 36 & 6 & $\begin{array}{l}\text { Low } \\
\text { risk }\end{array}$ \\
\hline $\begin{array}{l}\text { Krause, } \\
2015\end{array}$ & Uganda & CS & Depression & $\begin{array}{l}\text { GHQ- } \\
28\end{array}$ & 21 & 20 & 95 & $\begin{array}{l}\text { Low } \\
\text { risk }\end{array}$ \\
\hline
\end{tabular}


Table 2

Subgroup analysis by sample size, study quality and publication year

\begin{tabular}{|c|c|c|c|c|c|}
\hline Subgroup & $\begin{array}{l}\text { Number of } \\
\text { Studies }\end{array}$ & Pooled prevalence & $95 \% \mathrm{Cl}$ & $1^{2}$ & P-value \\
\hline \multicolumn{6}{|l|}{ Sample size } \\
\hline Small (< median) & 6 & 0.79 & $0.51-0.97$ & 95.4 & $<0.001$ \\
\hline Large ( $\geq$ median) & 9 & 0.67 & $0.54-0.80$ & 96.99 & $<0.001$ \\
\hline \multicolumn{6}{|l|}{ Study quality } \\
\hline Low risk & 8 & 0.66 & $0.44-85$ & 93.6 & $<0.001$ \\
\hline High risk & 7 & 0.89 & $0.77-0.98$ & 95.1 & $<0.001$ \\
\hline \multicolumn{6}{|l|}{ Publication year } \\
\hline $2011-2016$ & 9 & 0.73 & $0.54-0.89$ & 92.26 & $<0.001$ \\
\hline 2017-2019 & 6 & 0.70 & $0.53-0.85$ & 95.1 & $<0.001$ \\
\hline \multicolumn{6}{|l|}{ Tool } \\
\hline BDI-21 & 3 & 0.84 & $0.36-100$ & - & - \\
\hline PHQ-9 & 4 & 0.75 & $0.58-0.89$ & 97.01 & $<0.001$ \\
\hline GHQ-28 & 3 & 0.69 & $0.34-0.95$ & - & - \\
\hline CES-D & 4 & 0.57 & $0.30-0.81$ & 86.97 & $<0.001$ \\
\hline HSC & 1 & 0.85 & $0.74-.092$ & - & - \\
\hline \multicolumn{6}{|l|}{ Country } \\
\hline Ethiopia & 5 & 0.86 & $0.69-0.97$ & 95.04 & $<0.001$ \\
\hline Kenya & 1 & 0.73 & $0.61-0.82$ & - & - \\
\hline Nigeria & 1 & 0.37 & $0.28-0.47$ & 95.84 & $<0.001$ \\
\hline Sudan & 2 & 0.53 & $0.45-60$ & - & - \\
\hline Tanzania & 4 & 0.57 & $0.30-0.81$ & 96.01 & $<0.001$ \\
\hline Uganda & 2 & 0.88 & $0.80-0.95$ & - & - \\
\hline
\end{tabular}

\section{Prevalence of depression}

The overall pooled prevalence of depression was found to be $72 \%$ (95\% Cl; $60 \%-83 \%$ ) (Fig. 2). We found evidence of significant heterogeneity $\left(l^{2}=94.83 \%\right.$ and $\left.p<0.001\right)$. 


\section{Subgroup analysis}

Subgroup analysis demonstrated higher pooled prevalence among studies with smaller sample size (pooled prevalence $=79 \%$ (95\% Cl: 51\%-97\%)) and publication year between 2011-2016 (pooled prevalence $=73 \%(95 \% \mathrm{Cl}: 54 \%-89 \%)$ ) as compared to studies with higher sample size (pooled prevalence $=67 \%(54 \%-80 \%))$ and publication year between $2017-2019$ (pooled prevalence $=70 \%(95 \%$ Cl: 53\%-85\%)) respectively (Table: 2 ).

\section{Publication bias and sensitivity test}

There was no evidence of publication bias from the visual inspection of the funnel plot (Fig. 3) and Egger's test $(P<0.654)]$. The sensitivity analysis showed that none of the point estimates was outside of the overall $95 \%$ confidence interval confirming that there was no influential study. Thus, the pooled estimates based on the 15 studies could be important.

\section{Discussion}

In this systematic review and meta-analysis, majority $[72 \%$ (95\% Cl; $60 \%-83 \%)]$ of women with obstetric fistula experienced depression. This result is five times higher than the pooled prevalence of depression among the general population $14.4 \%(95 \% \mathrm{Cl}: 11.1-11.7 \%)(23,27,54)$. This may be due to the severity of the illness and its negative life events. Previous studies showed that negative life events, such as relationship dissolution, illness, and death, were adversely affecting the mental health of individual (12, $28,37)$. This adverse effect has a dose-effect relationship between the numbers of stressful life events and mental illness. The negative life events of women with obstetric fistula is unbearable, where more than $85 \%$ of them experience fetal loss, $27 \%-69.2 \%$ divorced, up to $53 \%$ social exclusion and majority lack social support and depend on families $(23,27)$. These affect the fulfillments of the role of women with obstetrics fistula as a partner, wife, mother, and productive member of community and impair social relationships, which in turn, them at increased risk for mental illness such as depression $(12,28,37,55-$ 57). Evidence from previous meta-synthesis support the statistical finding of this meta-analysis and provided an evidence on the negative lived experience of women particularly change, in their marital status, role function, relationship, isolation, and economic deprivation. That is why the co-morbidity of psychosocial problem such as depression, anxiety, suicide and stigma were reported as not surprising $(55-58)$. From these meta-synthesis, it is also reported that women with obstetric fistula have also number of negative psycho-social problems on religious practices, feelings of shame, hopelessness, depression, post-traumatic stress, decreased self-esteem, suicidal ideation and psycho-somatic symptoms (55-57). This systematic review and meta-analysis implied that (i) the prevalence of depression among women with obstetric fistula was high, (ii) the need of screening for all women with obstetric fistula and (iii) the needs of managing co-morbid depression or integrated mental health care.

\section{Strengths and limitations of the study}


To our knowledge, this is the first systematic review and meta-analysis on the mental health of women with obstetrics fistula. Moreover, the inclusions' of all studies without the restrictions of country, year of publication and use of standardized tools are the strength of this study. In addition to this, we conducted subgroup analysis and sensitivity test to account for possible sources of heterogeneity across the studies. However, some limitations like exclusions of studies assessed with un described assessment tool may minimize the number of included studies. Use of reference lists and Google Scholar to include all the available studies may have possibility of having some overlooked articles. Lack of similar studies limits the discussion.

\section{Conclusion}

The pooled estimate prevalence of depression among women with obstetric fistula was high. Thus, authors' suggest the need of special attention to mange co-morbid depression among women with obstetric fistula, such as an integrated mental health care.

\section{Abbreviations}

\section{$\mathrm{BDI}-21$}

Beck Depression Inventory, CS:Cross-Sectional, CES-D:Center for Epidemiological Studies Depression Scale, Cl:Confidence Interval, CIDI:Composite International Diagnostic Interview, CRD:Centre for Reviews and Dissemination, DSH:Deliberate Self-Harm, DSM-IV:Diagnostic and Statistical Manual of Mental Disorders 4th edition, EJHD:Ethiopian Journal of Health Development, EJHS:Ethiopian Journal of Health Science, EMBASE:ExcerptaMedica database, HSC:Hopkins Symptom Checklist, PHQ-9:Patient Health Questionnaire-9, I2:Index of heterogeneity, ICD-10:Tenth Revision of the International Statistical Classification of Diseases and Related Health Problems, MEDLINE:Medical Literature Analysis and Retrieval System Online, MeSH:Medical Subject Headings, NSSI:non-suicidal self-injury, OR:Odd Ratio, PRISMA:Preferred Reporting Items for Systematic Review and Meta-Analysis, PROSPERO:International Prospective Register of Systematic Reviews, WHO:World Health Organization, SBQ-R:Suicidal Behaviour Questionnaire-Revised and, BSS:Beck-Suicide Scale.

\section{Declarations}

\section{Ethics approval and consent to participate}

Not applicable.

\section{Consent to publish}

Not applicable

\section{Availability of data and material}


All the available data were included.

\section{Competing interests}

\section{None declared}

\section{Funding}

This research received no grant from any funding agency.

\section{Authors' contributions}

BBB designed the systematic review and meta-analysis in collaboration with YDG. BBB developed the search strategy and drafted the protocol. YDG improved the drafted systematic review and meta-analysis. $B B B$ and YDG provided their expertise to the section of suicidal behaviours and methodological section. BBB and YDG performed search strategy and conducted data selection and extraction. All authors were involved in data analysis and interpretation of the results and write up the manuscript. All authors have read and approved the final manuscript.

\section{Acknowledgements}

Authors' gratitude goes to University of Gondar for office arrangement and motivational support to conduct this systematic review and meta-analysis.

\section{Authors' information's}

${ }^{1}$ University of Gondar College of Medicine and Health Science, School of Nursing, Gondar, Ethiopia

${ }^{2}$ Bahar Dar University, College of Medicine and Health Science, Department of Psychiatry Ethiopia.

\section{References}

1. Wall LL, Karshima JA, Kirschner C, Arrowsmith SD. The obstetric vesicovaginal fistula: characteristics of 899 patients from Jos, Nigeria. American journal of obstetrics and gynecology. 2004;190(4):10119.

2. Wall LL. Obstetric fistula is a "neglected tropical disease". PLoS neglected tropical diseases. 2012;6(8):e1769.

3. Browning A. Obstetric fistula: clinical considerations in the creation of a new urethra and the management of a subsequent pregnancy. Int J Gynaecol Obstet. 2007;99 Suppl 1:S94-7. 
4. Baker Z, Bellows B, Bach R, Warren C. Barriers to obstetric fistula treatment in low-income countries: a systematic review. Trop Med Int Health. 2017;22(8):938-59.

5. Nour NM. Child marriage: a silent health and human rights issue. Rev Obstet Gynecol. 2009;2(1):51-6.

6. Consequences of genital mutilation. Womens Health Newsl. 1998(36):5.

7. Filippi V, Chou D, Ronsmans C, Graham W, Say L. Levels and Causes of Maternal Mortality and Morbidity. In: Black RE, Laxminarayan R, Temmerman M, Walker N, editors. Reproductive, Maternal, Newborn, and Child Health: Disease Control Priorities, Third Edition (Volume 2). Washington (DC): The International Bank for Reconstruction and Development / The World Bank (c) 2016 International Bank for Reconstruction and Development / The World Bank.; 2016.

8. Ballard K, Ayenachew F, Wright J, Atnafu H. Prevalence of obstetric fistula and symptomatic pelvic organ prolapse in rural Ethiopia. International urogynecology journal. 2016;27(7):1063-7.

9. Jokhio AH, Rizvi RM, Rizvi J, MacArthur C. Prevalence of obstetric fistula: a population-based study in rural Pakistan. BJOG : an international journal of obstetrics and gynaecology. 2014;121(8):103946.

10. Biadgilign S, Lakew Y, Reda AA, Deribe K. A population based survey in Ethiopia using questionnaire as proxy to estimate obstetric fistula prevalence: results from demographic and health survey. Reproductive health. 2013;10:14.

11. Adler AJ, Ronsmans C, Calvert C, Filippi V. Estimating the prevalence of obstetric fistula: a systematic review and meta-analysis. BMC pregnancy and childbirth. 2013;13:246.

12. Dennis AC, Wilson SM, Mosha MV, Masenga GG, Sikkema KJ, Terroso KE, et al. Experiences of social support among women presenting for obstetric fistula repair surgery in Tanzania. Int J Womens Health. 2016;8:429-39.

13. Mahran M. Medical dangers of female circumcision. IPPF Med Bull. 1981;15(2):1-3.

14. Krause HG, Hall BA, Ng SK, Natukunda H, Singasi I, Goh JTW. Mental health screening in women with severe pelvic organ prolapse, chronic fourth-degree obstetric tear and genital tract fistula in western Uganda. International urogynecology journal. 2017;28(6):893-7.

15. Mwanri L, Gatwiri GJ. Injured bodies, damaged lives: experiences and narratives of Kenyan women with obstetric fistula and Female Genital Mutilation/Cutting. Reproductive health. 2017;14(1):38.

16. Muleta M, Hamlin EC, Fantahun M, Kennedy RC, Tafesse B. Health and social problems encountered by treated and untreated obstetric fistula patients in rural Ethiopia. J Obstet Gynaecol Can. 2008;30(1):44-50.

17. Watt MH, Mosha MV, Platt AC, Sikkema KJ, Wilson SM, Turner EL, et al. A nurse-delivered mental health intervention for obstetric fistula patients in Tanzania: results of a pilot randomized controlled trial. Pilot Feasibility Stud. 2017;3:35.

18. Wilson SM, Sikkema KJ, Watt MH, Masenga GG. Psychological Symptoms Among Obstetric Fistula Patients Compared to Gynecology Outpatients in Tanzania. Int J Behav Med. 2015;22(5):605-13. 
19. Wilson SM, Sikkema KJ, Watt MH, Masenga GG, Mosha MV. Psychological Symptoms and Social Functioning Following Repair of Obstetric Fistula in a Low-Income Setting. Matern Child Health J. 2016;20(5):941-5.

20. Alio AP, Merrell L, Roxburgh K, Clayton HB, Marty PJ, Bomboka L, et al. The psychosocial impact of vesico-vaginal fistula in Niger. Arch Gynecol Obstet. 2011;284(2):371-8.

21. Hardee K, Gay J, Blanc AK. Maternal morbidity: neglected dimension of safe motherhood in the developing world. Glob Public Health. 2012;7(6):603-17.

22. Dohrenwend BP. A psychosocial perspective on the past and future of psychiatric epidemiology. American journal of epidemiology. 1998;147(3):222-31.

23. Steel Z, Marnane C, Iranpour C, Chey T, Jackson JW, Patel V, et al. The global prevalence of common mental disorders: a systematic review and meta-analysis 1980-2013. International journal of epidemiology. 2014;43(2):476-93.

24. Rahman A, Fisher J, Bower P, Luchters S, Tran T, Yasamy MT, et al. Interventions for common perinatal mental disorders in women in low- and middle-income countries: a systematic review and meta-analysis. Bulletin of the World Health Organization. 2013;91(8):593-601i.

25. Clarke K, King M, Prost A. Psychosocial interventions for perinatal common mental disorders delivered by providers who are not mental health specialists in low- and middle-income countries: a systematic review and meta-analysis. PLoS medicine. 2013;10(10):e1001541.

26. Patel V, Chisholm D, Parikh R, Charlson FJ, Degenhardt L, Dua T, et al. Global Priorities for Addressing the Burden of Mental, Neurological, and Substance Use Disorders. In: Patel V, Chisholm D, Dua T, Laxminarayan R, Medina-Mora ME, editors. Mental, Neurological, and Substance Use Disorders: Disease Control Priorities, Third Edition (Volume 4). Washington (DC): The International Bank for Reconstruction and Development / The World Bank

(c) 2016 International Bank for Reconstruction and Development / The World Bank.; 2016.

27. Organization WH. Depression and Other Common Mental Disorders: Global Health Estimates. Geneva: 2017.

28. Weston K, Mutiso S, Mwangi JW, Qureshi Z, Beard J, Venkat P. Depression among women with obstetric fistula in Kenya. Int J Gynaecol Obstet. 2011;115(1):31-3.

29. Siddle K, Mwambingu S, Malinga T, Fiander A. Psychosocial impact of obstetric fistula in women presenting for surgical care in Tanzania. International urogynecology journal. 2013;24(7):1215-20.

30. Goh JT, Sloane KM, Krause HG, Browning A, Akhter S. Mental health screening in women with genital tract fistulae. BJOG : an international journal of obstetrics and gynaecology. 2005;112(9):1328-30.

31. Ojengbede OA, Baba Y, Morhason-Bello IO, Armah M, Dimiti A, Buwa D, et al. Group psychological therapy in obstetric fistula care: a complementary recipe for the accompanying mental ill health morbidities? Afr J Reprod Health. 2014;18(1):155-9.

32. S. Ahmed * SAH. Social and economic consequences of obstetric fistula: Life changed forever? International Journal of Gynecologyand Obstetrics. 2007;99:510-5. 
33. Hannah Mafo Degge MHaML. An integrative review on women living with obstetric fistula and after treatment experiences. Journal of Clinical Nursing. 2016;26:Journal of Clinical Nursing.

34. Bitew T. Prevalence and risk factors of depression in Ethiopia: a review. Ethiopian journal of health sciences. 2014;24(2):161-9.

35. Biratu A, Haile D. Prevalence of antenatal depression and associated factors among pregnant women in Addis Ababa, Ethiopia: a cross-sectional study. Reproductive health. 2015;12:99.

36. Keynejad RC, Dua T, Barbui C, Thornicroft G. WHO Mental Health Gap Action Programme (mhGAP) Intervention Guide: a systematic review of evidence from low and middle-income countries. Evidencebased mental health. 2018;21(1):30-4.

37. Zeleke BM, Ayele TA, Woldetsadik MA, Bisetegn TA, Adane AA. Depression among women with obstetric fistula, and pelvic organ prolapse in northwest Ethiopia. BMC psychiatry. 2013;13:236.

38. Browning A, Fentahun W, Goh JT. The impact of surgical treatment on the mental health of women with obstetric fistula. BJOG : an international journal of obstetrics and gynaecology. 2007;114(11):1439-41.

39. Sun LM, Liang JA, Lin CL, Sun S, Kao CH. Risk of mood disorders in patients with colorectal cancer. Journal of affective disorders. 2017;218:59-65.

40. Britteon P, Cullum N, Sutton M. Association between psychological health and wound complications after surgery. The British journal of surgery. 2017;104(6):769-76.

41. al Ae. Trajectories of women's physical and psychosocial health following obstetric fistula repair in Uganda: a longitudinal study. Tropical Medicine and International Health. 2019;24(1):53-64.

42. Tsegaw MG. "Prevalence of Depression and Associated Factors among Patients with Obstetric Fistula at Hamlin Fistula Treatment Centers, Ethiopia: A Facility Based Cross-sectional Study.". American Journal of Public Health Research. 2018;5(6):215-21.

43. Mavhandu-Mudzusi Ba. Effects of surgical repair of obstetric fistula on severity of depression and anxiety in Ethiopia. BMC psychiatry. 2019;19(58):1-8.

44. Mavros MN, Athanasiou S, Gkegkes ID, Polyzos KA, Peppas G, Falagas ME. Do psychological variables affect early surgical recovery? PloS one. 2011;6(5):e20306.

45. Hoogewerf CJ, van Baar ME, Middelkoop E, van Loey NE. Impact of facial burns: relationship between depressive symptoms, self-esteem and scar severity. General hospital psychiatry. 2014;36(3):271-6.

46. Moher D, Shamseer, L., Clarke, M., Ghersi, D., Liberati, A., Petticrew, M., et al. Preferred reporting items for systematic review and meta-analysis protocols (PRISMA-P) 2015 statement. Syst. Rev Syst Rev. 2015;4(1).

47. Munn Z MS, Lisy K, Riitano D, Tufanaru C. Methodological guidance for systematic reviews of observational epidemiological studies reporting prevalence and incidence data. Int J Evid Based Healthc. 2014;13(3):147-53. 
48. Berkey CS HD, Mosteller F, Colditz GA. A random-effects regression model for meta-analysis. Statistics in medicine. 1995;14(4):395-411.

49. Worku DK, Yifru YM, Postels DG, Gashe FE. Prevalence of depression in Parkinson's disease patients in Ethiopia. Journal of clinical movement disorders. 2014;1:10.

50. Tsegabrhan H, Negash A, Tesfay K, Abera M. Co-morbidity of depression and epilepsy in Jimma University specialized hospital, Southwest Ethiopia. Neurology India. 2014;62(6):649-55.

51. Higgins JP TS. Quantifying heterogeneity in a meta-analysis. Statistics in medicine. Statistics in medicine 2002;21(11).

52. Dejenie Habtewold T, Radie YT, Sharew NT. Prevalence of Depression among Type 2 Diabetic Outpatients in Black Lion General Specialized Hospital, Addis Ababa, Ethiopia. Depression research and treatment. 2015;2015:184902.

53. Egger M DSG, Schneider M, Minder C. Bias in meta-analysis detected by a simple, graphical test. BMJ (Clinical research ed). 1997;315(7109):629-34.

54. Y. Grace WWTL, Y. Lu, S. Cyrus, W. Melvyn et al. "Prevalence of Depression in the Community from 30 Countries between 1994 and 2014" Scientific Reports, vol. 8, p. 2861, 2018.

55. Wall LL. Obstetric vesicovaginal fi stula as an international public-health problem. Lancet 2006;368:1201-09.

56. Karen M. Roush. Social Implications of Obstetric Fistula: An Integrative Review. J Midwifery Womens Health. 2009;54:21-33.

57. Ladeisha Lombard JdSJ, Rosemary Geddes, Alison M. El Ayadi3 and Liz Grant. Systematic Review. Rehabilitation experiences after obstetric fistula repair: systematic review of qualitative studies. Tropical Medicine and International Health. 2015;20(5):554-68.

58. al Be. Consequences of obstetric fistula in sub Sahara African countries, from patients' perspective: a systematic review of qualitative studies. BMC Women's Health (2018) 18:106 https://doiorg/101186/s12905-018-0605-1.

\section{Figures}




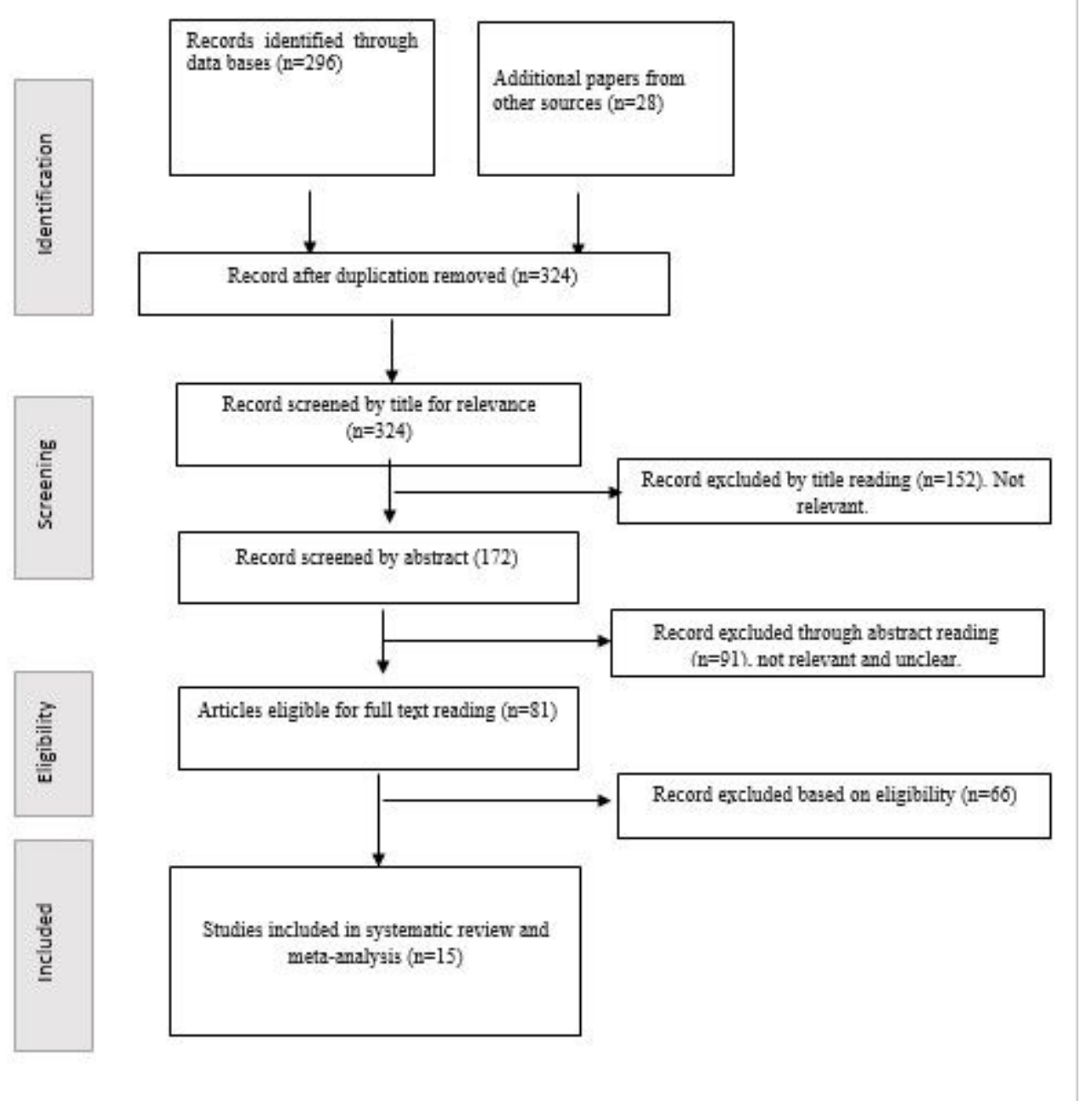

Figure 1

Flow diagram of included studies 


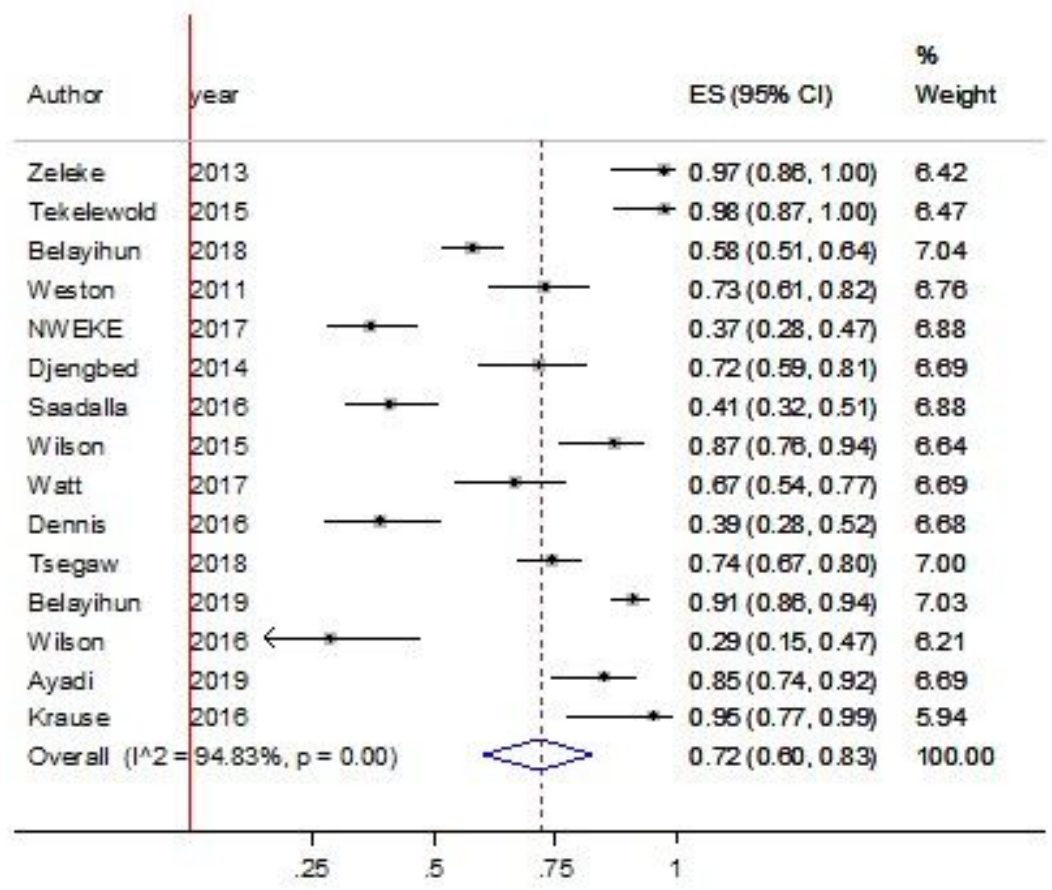

Figure 2

Forest plot presenting prevalence of depression using random effect models with $95 \% \mathrm{Cl}$.

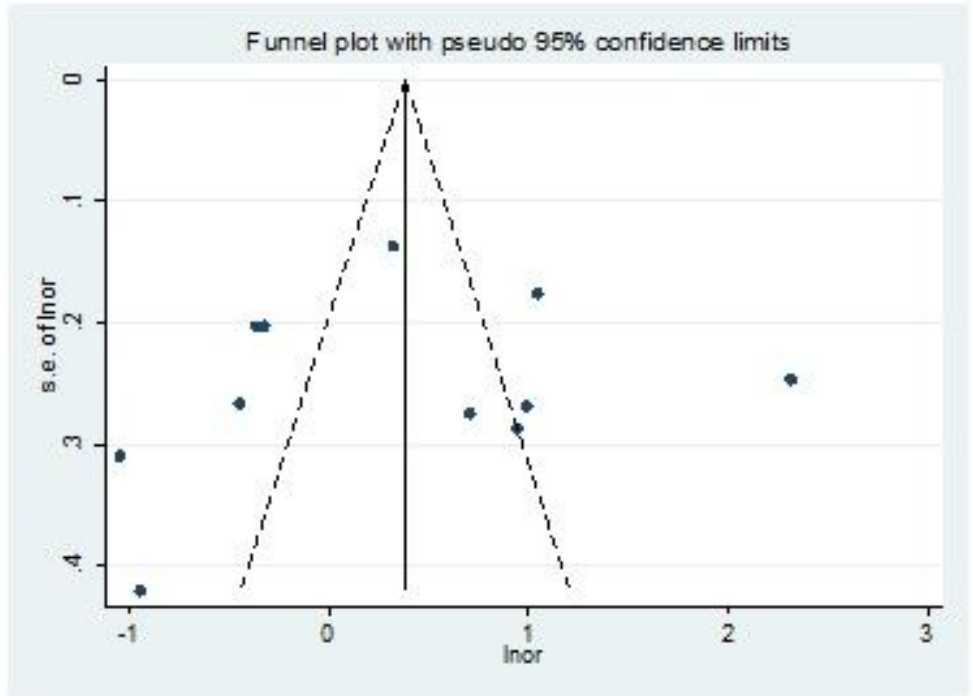

Figure 3

Funnel plot with pseudo $95 \%$ confidence interval that investigated the heterogeneity of the pooled prevalence of depression. 


\section{Supplementary Files}

This is a list of supplementary files associated with this preprint. Click to download.

- TableS1supportinginformation.docx 